\title{
Treating pyogenic liver abscesses secondary to diverticulitis in a patient using immunosuppressants for Crohn's disease by performing a sigmoid colectomy
}

\author{
Marin Pielage, ${ }^{1}$ Sanne Vogels, ${ }^{1}$ Rigo Hoencamp, ${ }^{1,2,3,4}$ Jephta van den Bremer ${ }^{1}$
}

'Department of Surgery, Alrijne Hospital Leiderdorp, Leiderdorp, The Netherlands

${ }^{2}$ Defense Healthcare

Organization, Ministry

of Defense, Utrecht, The

Netherlands

${ }^{3}$ Department of Surgery, Leiden University Medical Center, Leiden, The Netherlands

${ }^{4}$ Department of Trauma Surgery, Erasmus Medical Center, Rotterdam, The Netherlands

Correspondence to Mr Rigo Hoencamp: rhoencamp@alrijne.nl

MP and SV are joint first authors.

Accepted 15 October 2019

Check for updates

(c) BMJ Publishing Group Limited 2019. No commercial re-use. See rights and permissions. Published by BMJ.

To cite: Pielage $M$, Vogels $S$, Hoencamp $\mathrm{R}$, et al. BMJ

Case Rep 2019:12:e231031.

doi:10.1136/bcr-2019-

231031

\section{SUMMARY}

Pyogenic liver abscess (PLA) formation is a rare complication of Crohn's disease (CD). As symptoms often mimic a CD exacerbation, diagnosis can be delayed leading to severe disease. The current case report describes a case of a patient with a history of CD that was admitted with multiple PLAs, which persisted despite percutaneous drainage combined with antibiotics. After a sigmoid resection, the liver abscesses diminished rapidly.

\section{BACKGROUND}

Crohn's disease (CD) is a chronic inflammatory bowel disease potentially affecting all portions of the gastrointestinal tract. Typically, these inflammatory lesions initiate as mucosal ulcers that progressively transform into greater transmural inflammations, appearing in the intestines as a discontinuous pattern known as skip lesions. When analysed endoscopically, affected mucosa of the intestinal wall can be described as having a cobblestone appearance with long, deep linear ulcers.

$\mathrm{CD}$ is also known to affect extraintestinal systems and is thereby considered a systemic disease. The most prevalent complication is the formation of intra-abdominal abscesses due to perforating intestinal lesions. Moreover, hepatobiliary complications like primary sclerosing cholangitis, cholelithiasis and liver steatosis are well-studied manifestations of CD. ${ }^{1} \mathrm{~A}$ more rare infectious complication is the development of a pyogenic liver abscess (PLA), only documented in several case studies. ${ }^{2-11}$

PLA formation is a consequence of microbial contamination of the liver parenchyma. Often, these liver abscess form secondary to infectious conditions in which infectious agents seed bile ducts or vessels; for example, with cholecystitis, cholangitis or intra-abdominal infections that drain via the portal vein. Though active lesions of CD also contaminate the portal vein with microbial agents, the formation of PLA remains limited in this group of patients. On the other hand, the diagnosis of PLA in this group of patients remains challenging as symptoms and findings of PLA can mimic a CD exacerbation. The distinction is made based on radiologically guided percutaneous aspiration and drainage. Subsequently, suitable antimicrobial therapy is adapted on cultures and antibiograms. Yet, the most appropriate treatment options in patients with both CD and PLA remain debatable. The current report presents a case of a patient with CD and liver abscesses in which antimicrobial therapy and percutaneous drainage were not considered sufficient and a sigmoid colectomy was performed.

\section{CASE PRESENTATION}

A 54-year-old man was admitted to the department of gastroenterology with a 2-week history of overall malaise, lower back pain, dizziness, shivers and night sweats. Patient's history solely stated a 6-year treatment of CD that was stable over the past period with infliximab and azathioprine. On physical examination, vital signs were stable. A solid mass was felt in the left lower quadrant on palpation of the abdomen; no abdominal tenderness was reported.

\section{INVESTIGATIONS}

The laboratory results revealed a C-reactive protein of $314 \mathrm{mg} / \mathrm{L}$, a white blood cell count of $15.3 \times 10^{9} / \mathrm{L}$ with predominantly neutrophilia and an erythrocyte sedimentation rate of $67 \mathrm{~mm} /$ hour. A CT scan revealed multiple abnormalities in the right lobe of the liver, suspect for abscesses (figures 1 and 2). Moreover, a thickening of the wall in the transition of the descendent colon to sigmoid was found, which did not significantly differ compared with a

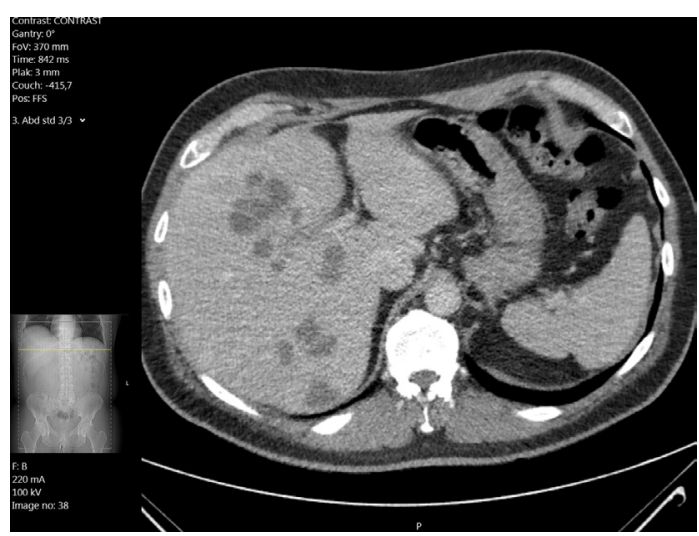

Figure 1 Axial CT abdomen on admission, revealing multiple abscesses within the liver. 


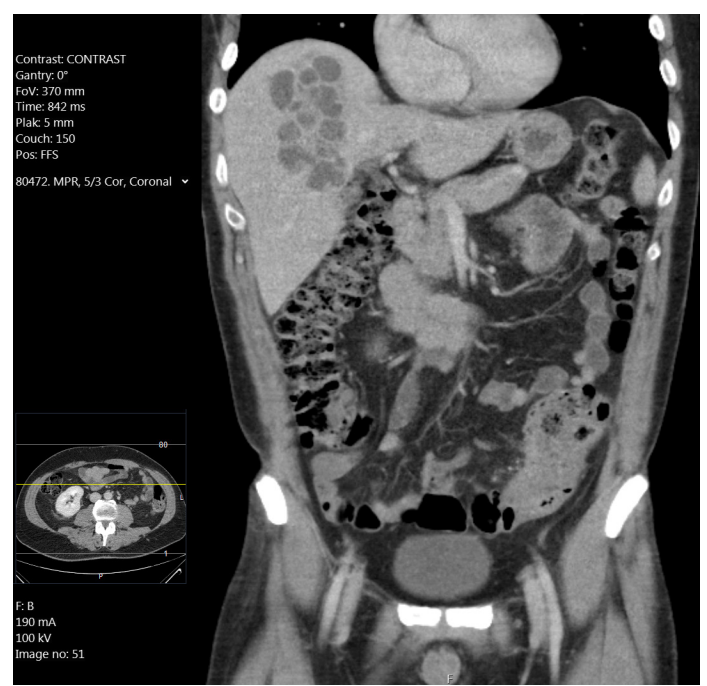

Figure 2 Coronal CT abdomen on admission, illustrating the multinodular abscesses within the liver. Additionally, the sigmoid is illustrated as well, which was reported to have wall thickening.

former scan of 2012. After collecting blood cultures, antibiotic treatment was initiated using cefuroxime $1500 \mathrm{mg}$, metronidazole $500 \mathrm{mg}$ and a single dose of gentamicin $400 \mathrm{mg}$ intravenous.

\section{TREATMENT}

After admission, immunosuppressants were paused and an ultrasound-guided percutaneous drainage of one of the abscesses was performed. A percutaneous pigtail drain was left in situ to drain the largest abscess, which at that moment had a diameter of $10 \mathrm{~cm}$. The content of the abscess was cultured. Growth of Streptococcus intermedius was seen. Additionally, blood cultures turned out to contain S. milleri. While endocarditis was excluded, antibiotic treatment was switched to penicillin intravenous and metronidazole. Moreover, a colonoscopy was performed to visualise the entire colon. Only a mild diverticulitis of the sigmoid was seen. Subsequently, a positron emission tomography-CT scan was performed to localise any other primary infection sites, however no other sites of infections were found (figure 3).

The clinical condition of the patient did not improve with 3 weeks of antibiotic treatment and percutaneous drainage. Intravenous antibiotics were switched back to broad-spectrum cefuroxime $1500 \mathrm{mg}$ and metronidazole $500 \mathrm{mg}$ three times a day. After multidisciplinary consultation, we decided to resect the sigmoid, as previous imaging revealed mild diverticulitis rather than an active CD. Subsequently, a Hartmann's procedure was performed, during which no macroscopic anomalies of the sigmoid were seen. Inspection of the liver also did not show any abnormalities (figure 4). The percutaneous drains in the liver were left in situ and perioperative the patient received an additional dose of cefazoline $1000 \mathrm{mg}$. Postoperatively, the patient recovered rapidly and complications did not occur. Microscopic examination of the resected sigmoid colon showed excessive inflammation of the intestinal wall with small abscess formation, caused by diverticulitis. There were, however, no signs of malignancies, nor characteristics denoting an exacerbation of CD.

\section{OUTCOME AND FOLLOW-UP}

One week after the procedure, CT scan was repeated and showed a significant decrease in the size of the liver abscesses (figure 5). Following this, the percutaneous drains were removed. Two weeks after the surgical procedure, the patient was discharged from the

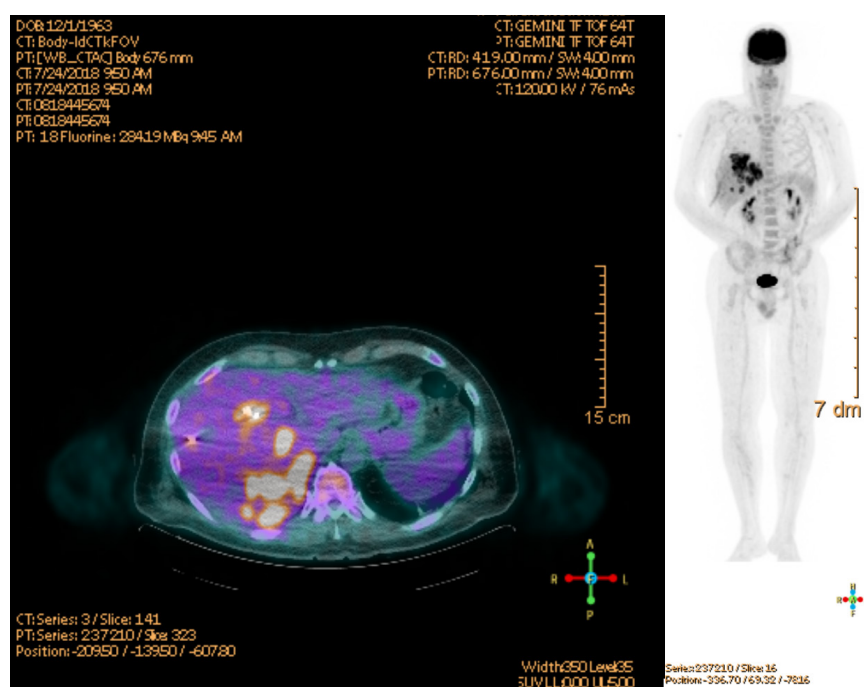

Figure 3 Positron emission tomography scan made to exclude any primary sites of infection. Aside from the uptake in the liver by the already diagnosed liver abscesses, only physiological uptake by all other organs was seen.

hospital with oral antibiotics for 4 weeks with clindamycin $600 \mathrm{mg}$ three times a day and ciprofloxacin $750 \mathrm{mg}$ two times a day. During routine control at the outpatient clinic, the patient did not report any complaints (figure 6). After 5 months, the colostomy was reversed with an end-to-end anastomosis of the colon.

\section{DISCUSSION}

PLA is a rare complication of CD, with a reported incidence up to 10-15 times higher in patients with $\mathrm{CD}$, compared with unaffected individuals. $^{312}$ Imaging more frequently reveals multiple abscesses rather than one solitary abscess. Predisposing factors for the development of PLA are thought to be intra-abdominal abscess formation, fistulas, mucosal ulceration, perforating disease, long-term treatment with steroids, diabetes mellitus and malnutrition. The precise pathophysiology is not known. ${ }^{12}$ However, the PLAs in the presented case are thought to be secondary to intra-abdominal abscess formation around the sigmoid due to diverticulitis, without evidence for an exacerbation of CD. It is hypothesised that translocation of bacteria from the $S$. milleri group from the infected area into the venous drainage of the sigmoid could have led to this complicated case of diverticulitis with PLA formation. This was also reported by Akuzawa et $a l^{13}$ and Murarka et al. ${ }^{14}$ Moreover, long-term usage of immunosuppressant presumably also contributed to the severity of the case.

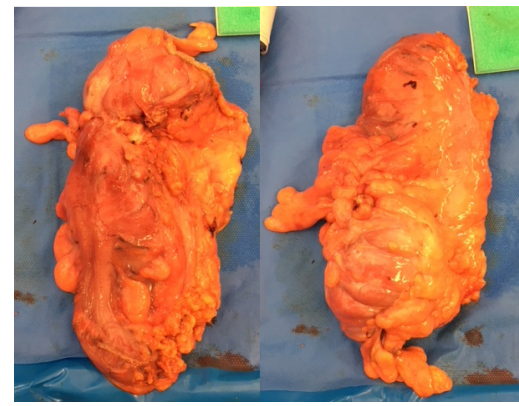

Figure 4 Perioperative pictures of the resected sigmoid, without any macroscopic abnormalities. 


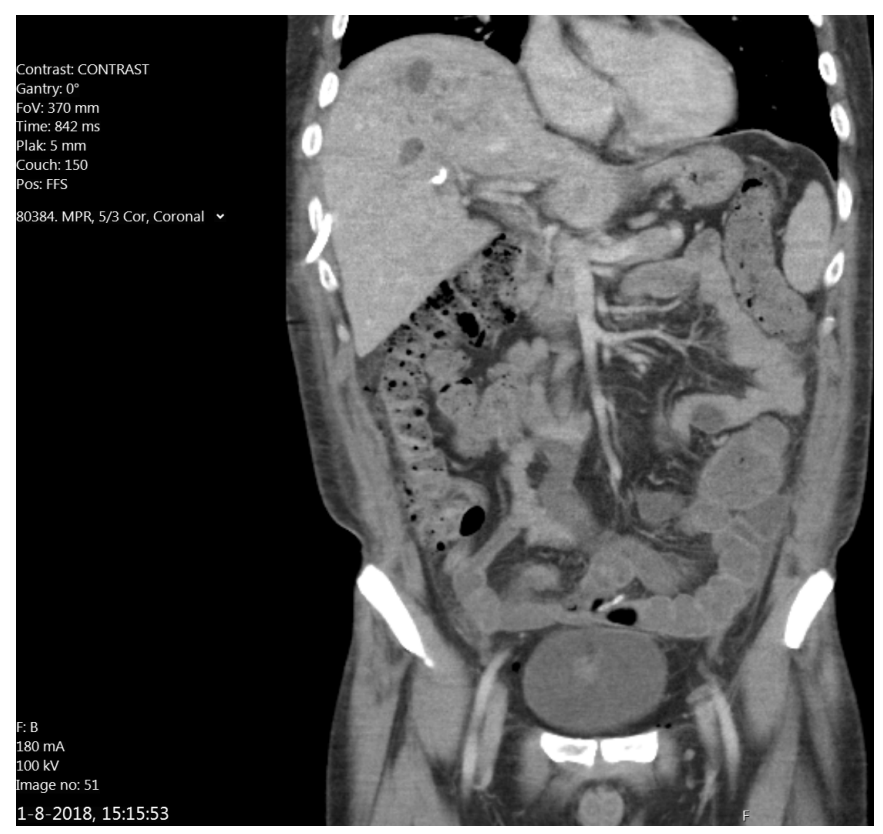

Figure 5 Coronal CT abdomen 1 week postoperatively, showing significant decrease in number and size of the previously found liver abscesses. subsequently the left-in drains were removed.

The use of imaging and diagnostic percutaneous drainage can aid in acquiring the adequate diagnosis. To further determine the underlying pathogen causing the abscesses, pus cultures and blood cultures can be collected. The most common pathogens reported are Klebsiella pneumoniae and Escherichia coli. Additionally, the majority of blood cultures grow gram-positive coccus, ${ }^{15}$ as was also found in the current case.

The majority of case reports ${ }^{2-5}$ 7-10 1215 describe that for the treatment of PLA the administration of antibiotics and drainage of the abscesses are often combined. Solely antibiotic treatment is only used for abscesses smaller than $5 \mathrm{~cm}$. As the PLA in the current report exceeded this size, merely antibiotic treatment was not considered an option. Percutaneous drainage or surgical incision and drainage can be used for abscesses exceeding 5 $\mathrm{cm}$. Percutaneous drainage via the pigtail catheter has a higher reported success rate in relation to single needle aspiration. ${ }^{16} 17$ When comparing to surgical drainage, pigtail drainage is less invasive, has a lower risk of adhesion formation and contamination,

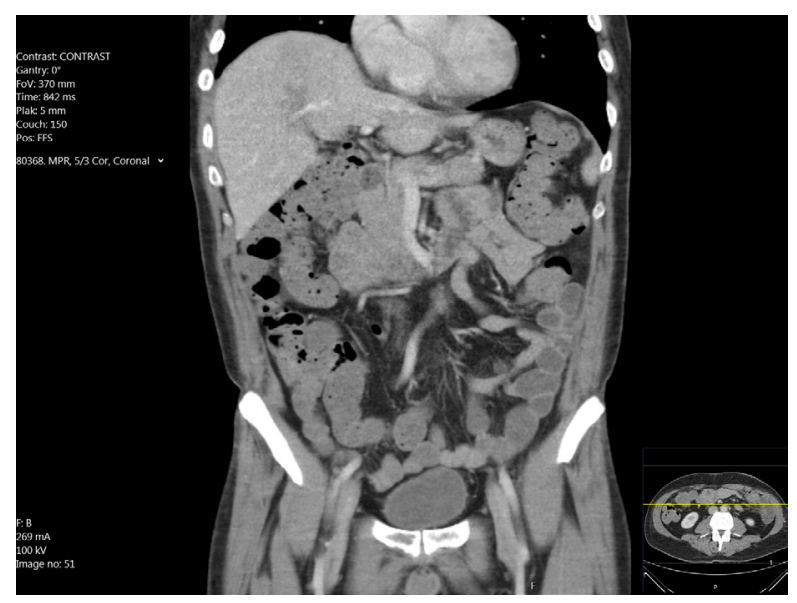

Figure 6 Coronal CT abdomen 5 weeks postoperatively, illustrating complete remission of the liver abscesses. and a relatively lower cost. Moreover, surgical drainage has a higher complication rate and is associated with higher morbidity and prolonged hospital stay. ${ }^{18}$ It is therefore that initial drainage in the presented case was attempted percutaneously.

Yet, a few studies report that when abscess exceeds $3 \mathrm{~cm}$ in size or is multiloculated, surgical intervention is preferred. ${ }^{1920}$ The current report illustrates a case in which this statement is supported, especially since the above-mentioned algorithm was followed without success. The patient had multilocular abscesses ranging from 2 to $10 \mathrm{~cm}$ in size, that only resolved after surgical resection. Regardless of the higher morbidity rates and prolonged hospital stay, this case demonstrates that surgical intervention, with resection of an inflamed colon, was a more optimal treatment and should thereby definitely be considered in patients with multilocular PLA.

\section{Learning points}

- Diverticulitis of the sigmoid colon should be considered as causative pathology in patients presenting with multiple pyogenic liver abscesses (PLAs) and a history of Crohn's disease that is in full remission with immunosuppression.

- PLAs secondary to abdominal abscesses are thought to result from bacterial translocation and are generally treated with administration of antibiotics and/or drainage of the abscesses.

- When the abscesses exceed $3 \mathrm{~cm}$ in size and are multilocular, resection of the inflamed colon can be a treatment option of value.

Contributors MP and SV contributed equally to this paper, by being responsible for all data collection, reporting these findings and the literature review, and editing/ revising all versions. RH contributed by planning all deadlines, edit the work of MP and SV and support submission in the current platform. JB contributed by being closely involved with the treatment of the patient, edit the work of MP and SV and taking the overall leading role.

Funding The authors have not declared a specific grant for this research from any funding agency in the public, commercial or not-for-profit sectors.

Competing interests None declared.

Patient consent for publication Obtained.

Provenance and peer review Not commissioned; externally peer reviewed.

\section{REFERENCES}

1 Fousekis FS, Theopistos VI, Katsanos KH, et al. Hepatobiliary manifestations and complications in inflammatory bowel disease: a review. Gastroenterology Research 2018;11:83-94.

2 Baca B, Hamzaoğlu I, Karahasanoğlu T, et al. Laparoscopic treatment of pyogenic liver abscess complicating Crohn's disease: a case report. Turk J Gastroenterol 2007;18:58-61.

3 McGreal S, Sayers R, Wurm P, et al. Crohn's disease presenting with pyogenic liver abscess: a case report. Case Rep Gastrointest Med 2012;2012:762480.

4 Margalit M, Elinav $\mathrm{H}$, Ilan Y, et al. Liver abscess in inflammatory bowel disease: report of two cases and review of the literature. J Gastroenterol Hepatol 2004;19:1338-42.

5 Narayanan S, Madda JP, Johny M, et al. Crohn's disease presenting as pyogenic liver abscess with review of previous case reports. Am J Gastroenterol 1998;93:2607-9.

6 Talwar A, Edwards D, Moran B. Hepatic abscesses as the primary presentation of Crohn's disease. J R Army Med Corps 2000;146:37-8.

7 Karaca C, Pinarbaşi B, Danalioğlu A, et al. Liver abscess as a rare complication of Crohn's disease: a case report. Turk J Gastroenterol 2004;15:45-8.

8 Kreuzpaintner G, Schmidt WU, West TB, et al. Two large liver abscesses complicating Crohn's disease. Z Gastroenterol 2000;38:837-40.

9 Kotanagi $\mathrm{H}$, Sone S, Fukuoka T, et al. Liver abscess as the initial manifestation of colonic Crohn's disease: report of a case. Jpn J Surg 1991;21:348-51.

10 Togashi J, Sugawara Y, Akamatsu N, et al. Resection of a methicillin-resistant Staphylococcus aureus liver abscess in a patient with Crohn's disease under infliximab treatment: a case report. J Med Case Rep 2013;7.

11 Vakil N, Hayne G, Sharma A, et al. Liver abscess in Crohn's disease. Am J Gastroenterol 1994;89:1090-5. 


\section{Novel treatment (new drug/intervention; established drug/procedure in new situation)}

12 Lin J-N, Lin C-L, Lin M-C, et al. Pyogenic liver abscess in patients with inflammatory bowel disease: a nationwide cohort study. Liver Int 2016;36:136-44.

13 Akuzawa N, Hatori T, Kitahara Y, et al. Multiple liver abscesses and bacteremia caused by Streptococcus constellatus infection: a case report. Clin Case Rep 2017:5:69-74.

14 Murarka S, Pranav F, Dandavate V, et al. Pyogenic liver abscess secondary to disseminated Streptococcus anginosus from sigmoid diverticulitis. J Glob Infect Dis 2011:3:79-81.

15 Du Z-Q, Zhang L-N, Lu Q, Ren Y-F, et al. Clinical charateristics and outcome of pyogenic liver abscess with different size: 15 -year experience from a single center. $\mathrm{SCi}$ Rep 2016;6:35890.
16 Cai Y-L, Xiong X-Z, Lu J, et al. Percutaneous needle aspiration versus catheter drainage in the management of liver abscess: a systematic review and meta-analysis. HPB 2015;17:195-201.

17 Zerem E, Hadzic A. Sonographically guided percutaneous catheter drainage versus needle aspiration in the management of pyogenic liver abscess. American Journal of Roentgenology 2007;189:W138-42.

18 Mavilia MG, Molina M, Wu GY. The evolving nature of hepatic abscess: a review. J Clin Trans/ Hepatol 2016:4:158-68.

19 Hope WW, Vrochides D V, Newcomb WL, et al. Optimal treatment of hepatic abscess. Amerian Surg 2008;74:178-82.

20 Tan Y-M, Chung AY-F, Chow PK-H, et al. An appraisal of surgical and percutaneous drainage for pyogenic liver abscesses larger than $5 \mathrm{~cm}$. Ann Surg 2005;241:485-90.

Copyright 2019 BMJ Publishing Group. All rights reserved. For permission to reuse any of this content visit https://www.bmi.com/company/products-services/rights-and-licensing/permissions/

BMJ Case Report Fellows may re-use this article for personal use and teaching without any further permission.

Become a Fellow of BMJ Case Reports today and you can:

- Submit as many cases as you like

- Enjoy fast sympathetic peer review and rapid publication of accepted articles

- Access all the published articles

Re-use any of the published material for personal use and teaching without further permission

\section{Customer Service}

If you have any further queries about your subscription, please contact our customer services team on +44 (0) 2071111105 or via email at support@bmj.com.

Visit casereports.bmj.com for more articles like this and to become a Fellow 